Document downloaded from:

http://hdl.handle.net/10251/61315

This paper must be cited as:

Juan, M.; Joele, D. (2011). A comparative study of the sense of presence and anxiety in an invisible marker versus a marker Augmented Reality system for the treatment of phobia towards small animals. International Journal of Human-Computer Studies. 69(6):440-453. doi:10.1016/j.ijhcs.2011.03.002.

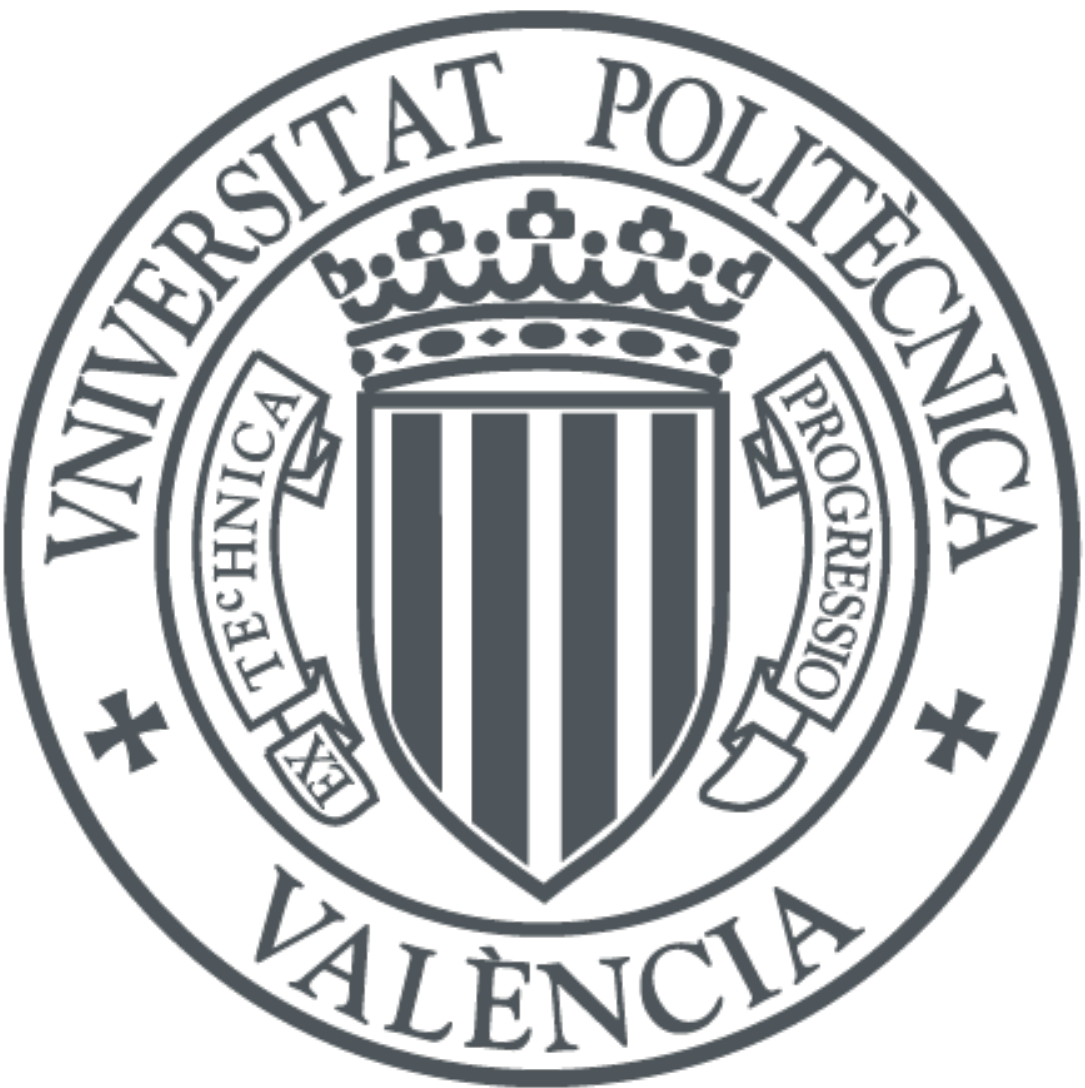

The final publication is available at

http://dx.doi.org/10.1016/j.ijhcs.2011.03.002

Copyright Elsevier

Additional Information 


\title{
A comparative study of the sense of presence and anxiety in an invisible marker versus a marker augmented reality system for the treatment of phobia towards small animals
}

\author{
Juan, M.Carmen ${ }^{1 *}$, Joele, Dennis ${ }^{2}$ \\ ${ }^{1}$ Instituto Universitario de Automática e Informática Industrial, Universitat Politècnica de València, \\ Camino de Vera, s/n. 46022 Valencia (Spain), mcarmen@ai2.upv.es \\ ${ }^{2}$ Mediamatics, Delft University of Technology (The Netherlands)
}

\begin{abstract}
Phobia towards small animals has been treated using exposure in vivo and virtual reality. Recently, augmented reality (AR) has also been presented as a suitable tool. The first AR system developed for this purpose used visible markers for tracking. In this first system, the presence of visible markers warns the user of the appearance of animals. To avoid this warning, this paper presents a second version in which the markers are invisible. First, the technical characteristics of a prototype are described. Second, a comparative study of the sense of presence and anxiety in a non-phobic population using the visible marker-tracking system and the invisible marker-tracking system is presented. Twenty-four participants used the two systems. The participants were asked to rate their anxiety level (from 0 to 10) at 8 different moments. Immediately after their experience, the participants were given the SUS questionnaire to assess their subjective sense of presence. The results indicate that the invisible marker-tracking system induces a similar or higher sense of presence than the visible marker-tracking system, and it also provokes a similar or higher level of anxiety in important steps for therapy. Moreover, $83.33 \%$ of the participants reported that they did not have the same sensations/surprise using the two systems, and they scored the advantage of using the invisible marker-tracking system at 5.19 \pm 2.25 (on a scale from 1 to 10). However, if only the group with higher fear levels is considered, $100 \%$ of the participants reported that they did not have the same sensations/surprise with the two systems, scoring the advantage of using the invisible marker-tracking system at $6.38 \pm 1.60$ (on a scale from 1 to 10 ).
\end{abstract}

Keywords--- augmented reality, invisible markers, phobia towards small animals

\section{Introduction}

This paper presents an augmented reality (AR) invisible marker-tracking system for the treatment of a phobia towards small animals. AR refers to the introduction of virtual content into the real world, that is, the user is seeing an image composed of a real image and virtual elements superimposed over it. A phobia towards small animals has traditionally been treated using exposure in vivo and also using virtual reality (VR) (e.g. Carlin, Hoffman \& Weghorst, 1997). Recently, the used of AR was presented as an alternative technology for this type of treatment (Juan et al., 2005; Botella et al., 2005). In that work, visible markers were used for tracking. In this paper, we present a second version of the visible marker-tracking AR system (VMARS) in which markers that are invisible to the naked eye (invisible markers) are used for tracking. The invisible marker-tracking AR system (IMARS) uses visible markers that are drawn with a special ink. In visible-marker-tracking systems, users relate the marker with the appearance of virtual elements. In our case, visible markers warn the patients of the appearance of animals and this could produce an initial anxiety without the appearance of the virtual element that really should produce this anxiety. We consider the non-appearance of the markers to be 
important, especially in some steps of the protocol followed during treatment. One common step of protocols for treating patients with phobia towards small animals is that patients have to search for the feared animal in the same way they would do so in their house. In our case, to simulate this search, we use three boxes, under one of which a marker is randomly placed. The animals will appear over the marker. At first, when the patient sees part of the marker, the system still does not show the animals, but the patient knows they will appear and s/he can decide not to finish raising the box, and the animals will not appear. If the marker were not visible, the patient would not know that the animals were going to appear, and when they did appear, they would produce the desired surprise. To avoid the one-to-one correspondence between the appearance of the marker and the appearance of the animals, it could be possible to pepper the environment with a large number of markers and just randomly make one active at any given time. But, in both cases, the markers appear artificially in the environment.

In our work, the primary hypothesis is that the IMARS will induce a similar or higher sense of presence and will provoke a similar or higher level of anxiety than the VMARS with non-phobic participants. Our first objective was to develop a new IMARS. Our second objective was to examine the sense of presence and the anxiety level using IMARS and VMARS.

This paper is organized as follows. Section 2 focuses on background about the use of VR for the treatment of a phobia towards small animals, the use of AR for psychological treatments, and tracking and registration methods used in AR. Section 3 presents the software and hardware requirements as well as the technical features of IMARS. Section 4 describes the participants and the procedure of the study. Section 5 presents the results of the study for the sense of presence and the level of anxiety. Finally, in section 6, we present our conclusions, the limitations of this study, and future work.

\section{Background}

\subsection{Treatment of phobia towards small animals using virtual reality exposure therapy}

Virtual reality exposure therapy (VRET) uses VR as a tool for therapy. The therapist has significant control and can manipulate the virtual environments to some extent. In addition, VRET is based on the assumption that virtual environments can elicit anxiety and provide the opportunity for habituation (Rothbaum et al., 1995). In the DSM-IV(APA, 2000, p. 820), anxiety is defined as an "apprehensive anticipation of future danger or misfortune accompanied by a feeling of dysphoria or somatic symptoms of tension". This definition implies that anxiety is a future-oriented state, which causes the organism to behave so that the danger can be averted. Several studies support the idea that emotions such as fear or anxiety, which are felt during immersion, are indicators of the sense of presence in virtual environments (Robillard et al., 2003; Schuemie et al., 2000; Renaud et al., 2002; Regenbrecht, Schubert \& Friedmann, 1999; Bouchard et al., 2008). The sense of presence has been defined as the psychological perception of "being in" or "existing in" the virtual environment in which one is immersed (Heeter, 1992; Witmer \& Singer, 1998).

People who suffer from arachnophobia or other types of phobia towards small animals become anxious when they are in a situation where these animals can appear. They suffer an unrealistic and excessive fear that makes life miserable. They are always frightened of seeing the animal they fear. Carlin, Hoffman \& Weghorst (1997) used immersive VR for exposure therapy. The first experiment was carried out at the U.W. Human Interface Technology laboratory (HITLab). The first patient treated with this system needed 12 VR therapy sessions of one hour. First, she started at the complete opposite end of the virtual world from the virtual spider. Slowly, she got a little closer. In later sessions, after she had lost some of her fear of spiders, she was sometimes encouraged to pick up the virtual spider and/or spider web with her cyberhand and place it in positions that were the most anxiety provoking. Other times, the experimenter controlled the spider's movements. Some virtual spiders were placed in a cupboard with a spider web. Other virtual spiders climbed or dropped from their thread from the ceiling to the virtual kitchen floor. Eventually, after getting used to them, she could tolerate holding and picking up the virtual spiders without panicking. She could also pull the spider's legs off. In another work, Renaud, Bouchard \& Proulx (2002) compared tracking behaviour with a 
virtual spider and a neutral target in fearful and non-fearful subjects. Garcia et al. (2002) explored whether VR exposure therapy was effective in the treatment of spider phobia. They compared a VR treatment condition versus a waiting list condition (participants waiting for treatment, but without treatment) in a between group design with 23 participants. Participants in the VR treatment group received an average of four one-hour exposure therapy sessions. VR exposure was effective in treating spider phobia compared to a control condition measured with a "fear of spiders questionnaire", a behavioural avoidance test, and severity ratings made by the clinician and an independent assessor. A total of $83 \%$ of the patients in the VR treatment group showed clinically significant improvement, that is, the VR treatment helped them to significantly reduce their fear and avoidance to spiders compared with $0 \%$ in the waiting list group, and no patients dropped out. Botella et al. (2004) presented a web system that used VR to treat a phobia towards small animals (cockroaches, spiders, and rats). Patients followed the treatment in their own homes. In this system, a typical kitchen was modelled. The system had different levels at which one or more small animals could appear. The animals randomly appeared when the user opened the door of a cupboard. It was possible to kill the animals and dispose of them in a dustbin.

\subsection{Augmented reality for psychological treatments}

Juan et al. (2005) and Botella et al. (2005) presented the first AR system for the treatment of phobias of cockroaches and spiders. In these works, they demonstrated that, with a single one-hour session, patients significantly reduced their fear and avoidance. Initially, the system was tested in a case study (Botella et al., 2005), and then it was tested on nine patients suffering from phobia towards small animals (Juan et al., 2005). In all cases, the patients reduced their fear and avoidance of the feared animal in only one session of treatment using the VMARS (Öst, Salkovskis \& Hellstroöm, 1991). Moreover, all of them were able to interact with the real animal after the treatment. Before the treatment, none of them were able to approach or interact with the live animal without fear.

For the treatment of acrophobia, Juan et al. (Juan et al., 2006) proposed the use of immersive photography in an AR system for the treatment of this phobia. In this system, forty-one participants without acrophobia walked around at the top of a staircase in both a real environment and in an immersive photography environment. Immediately after their experience, the participants were given the SUS questionnaire to assess their subjective sense of presence. The users' scores in the immersive photography environment were very high. The results indicated that the acrophobic context could be useful for the treatment of acrophobia. However, statistically significant differences were found between the real and immersive photography environments.

\subsection{Tracking and registration for augmented reality}

AR requires accurate position and orientation tracking in order to register the virtual elements in the real world. More specifically, 3D tracking aims at continuously recovering all six degrees of freedom that define the camera position and orientation relative to the scene. Magnetic, mechanical, acoustic, inertial, optical, or hybrid technologies have been used to achieve 3D tracking (Bowman et al., 2005). In this paper, we focus on optical techniques because the VMARS and the IMARS are marker-based. Optical methods can be divided into marker-based/fiducial-based or markerless/natural features-based (Fua \& Lepetit, 2007). The marker-based methods use fiducials that are easily recognizable landmarks or markers such as rectangles, circles, chessboards, etc. These fiducials can be passive (e.g., a printed marker) or active (e.g., a light-emitting diode). Hoff, Nguyen \& Lyon (1996) used the concentric contrasting circle fiducial, which was formed by placing a black ring on a white background, or vice-versa. State et al. (1996) used colour-coded fiducials. Each fiducial consisted of an inner dot and a surrounding outer ring; four different colours were used, and thus 12 unique fiducials could be created and identified based on their two colours. Cho, Lee \& Neumann (1998) introduced a system that uses several sizes for the fiducials (several coloured concentric rings). Claus \& Fitzigibbon (2004) used a machine-learning approach that significantly improved reliability over the 
use of ad hoc schemes as in previous methods. The fiducials consisted of black disks on a white background, and sample images were collected varying their perspective, scale, and lighting conditions, as well as negative training images. Koller et al. (1997) introduced square, black-on-white fiducials, which contained small red squares for their identification. Planar rectangular fiducials were also used in ARToolKit (Kato \& Billinghurst, 1999). ARToolKit has become very popular because it yields a robust, low-cost solution for real-time 3D tracking, and there is a software library that is publicly available. Nevertheless, ARToolKit is not the only library that uses planar rectangular fiducials. Other public libraries that use fiducials of this type can be cited, such as OsgART (Looser, 2007) or ARTag (Cawood \& Fiala, 2007). These libraries have been extensively used for the development of applications for different purposes.

With regard to markerless methods, it is not always possible to add visual markers in the real world, and in these cases, it could be possible to use features that are naturally present in the real world. Also, information about the 3D environment facilitates tracking. It is possible to classify these approaches depending on the nature of the image features to be used in either edge-based or texturebased methods (Fua \& Lepetit, 2007). For edge-based methods, one of the most popular approaches consists of looking for strong gradients in the image around a first estimation of the object pose, without explicitly extracting the contours (Armstrong \& Zisseman, 1995; Comport, Marchand, \& Chaumette, 2003; Drummond \& Cipolla, 2002; Harris, 1992; Marchand, Bouthemy, \& Chaumette, 2001; Vacchetti, Lepetit, \& Fua, 2004). For textured-based methods, information can be derived from optical flow (Basu, Essa, \& Pentland, 1996; DeCarlo \& Metaxas, 2000; Li, Roivainen, \& Forchheimer, 1993); template matching (Cascia, Sclaroff, \& Athitsos, 2000; Hager \& Belhumeur, 1998; Jurie \& Dhome, 2001, 2002); or interest-point correspondences (matching local features), which is considered to be the most effective for AR applications. There are also libraries based on markerless methods such as BazAR (Pilet, 2008). A more complete survey can be found in (Fua \& Lepetit, 2007).

Our work is not the first that uses infrared (IR) markers (Sauer et al., 2000; Tenmoku et al., 2003; Maeda et al., 2004; Nakazato et al., 2005; Yasumuro et al., 2005; Park and Park, 2004). Maeda et al. (2004) proposed a hybrid position and orientation tracking system. The system combined IR markers with a head-mounted stereo camera to detect the user's position, and an orientation sensor to measure the orientation of the user's head. In another work, Sauer et al. (2000) presented a tabletop setup called "augmented workspace". The user sat at the table and performed a manual task, guided by computer graphics overlaid onto his/her view. The system had three cameras. The third camera, which was used as the tracker camera, had a fisheye lens for a wide field of view and operated in the near infrared. The markers were retroreflective and were illuminated by a set of LEDs placed around the tracker camera's lens. The markers were arranged on a frame around the workspace. A third work that is worthy of mention is the one presented by Tenmoku et al. (2003). They measured the orientation of the user's viewpoint by an inertial sensor and measured the user's position using positioning infrastructures and a pedometer. The system specified the user's position using the position ID received from RFID tags or IrDA markers which were the components of positioning infrastructures. When the user moved away from them, the user's position was alternatively estimated by using a pedometer. In 2005, Nakazato et al. proposed a localization method based on the use of an IR camera and invisible markers consisting of translucent retro-reflectors. To extract the regions of the markers from the stably captured images, the camera captured the reflection of IR LEDs that were flashed on and off synchronously. In the same year, Yasumuro et al. presented a system that used visible and invisible projection onto physical target objects. They employed near-infrared pattern projection for triangulation so that scanning and updating the geometry data of the object was automatically performed in a background process. Finally, the work that is most related to ours is the one presented by Park \& Park (2004). They created the invisible markers using an IR fluorescent pen. The system consisted of a colour camera, an IR camera, and a half mirror. The two cameras were positioned on each side of the half mirror so that their optical centers coincided with each other. They tracked the invisible marker using the IR camera and visualized AR in the view of the colour camera. Our system also uses an infrared ink to draw the 
markers and two cameras (a colour camera and an IR camera), but we do not use the half mirror. Therefore, the hardware characteristics of the two systems are different.

\section{Material and methods}

\subsection{Hardware}

To capture the video, IMARS used a Dragonfly camera (Drag-Col-40, Point Grey Research). The dimensions of the Dragonfly camera are $63.5 \times 50.8 \mathrm{~mm}$. This camera is shown in Figure 1.a. This type of camera has a Sony $8.5 \mathrm{~mm}$ progressive scan CCD sensor, which delivers uncompressed 24-bit true colour images at a resolution of 640x480, with a maximum frame rate of $30 \mathrm{fps}$. The diagonal field of view (FOV) is 52 degrees. The infrared image was obtained using an IR camera, which is an IR bullet camera with an IR filter of $715 \mathrm{~nm}$. The IR bullet camera comes in a lipstick-sized tube that is 63.5 $\mathrm{mm}$ long, with a diameter of $20.6 \mathrm{~mm}$. This IR bullet camera is shown in Figure 1.b. The diagonal FOV of the camera is 92 degrees. The image sensor is $8.5 \mathrm{~mm} \mathrm{CCD}$, with a maximum frame rate of 30 fps in several image formats, among them 640x480. A cy-visor Head-Mounted Display (HMD) (800 H $\mathrm{x} 600 \mathrm{~V}, 31^{\circ} \mathrm{FOV}$ ) was used as the visualization hardware. Using a screen, the person in charge of the tests could see the same scene as the participant saw on the HMD. The two cameras were firmly attached to the front of the HMD. The capture and visualization system composed by the Dragonfly camera, the IR camera, and the HMD is shown in Figure 1.c. VMARS used the same colour camera and HMD as IMARS.

IMARS required a special ink for drawing the invisible markers. This special ink had a finite durability. This implies that the markers had to be drawn every week. We used ink that is invisible to ultraviolet light and the human eye. Ultraviolet light is below $400 \mathrm{~nm}$. The human eye can see light between $400 \mathrm{~nm}$ and $750 \mathrm{~nm}$. The ink that was used emits $840 \mathrm{~nm}$ frequency light and has a $793 \mathrm{~nm}$ absorption frequency, which lies in the infrared range. The ink falls into the near-IR spectrum, $750 \mathrm{~nm}$ to $3000 \mathrm{~nm}$. The ink itself is delivered in the form of an ink pen. The tip of the pen is fluorescent green to the human eye. Anything written on white paper cannot be seen by the human eye; however, when it is viewed with an infrared camera, the ink becomes visible. An external light source was not required.

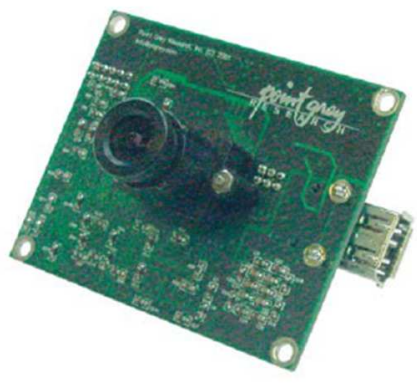

a)

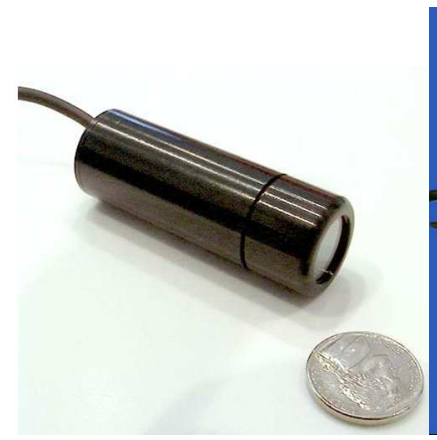

b)

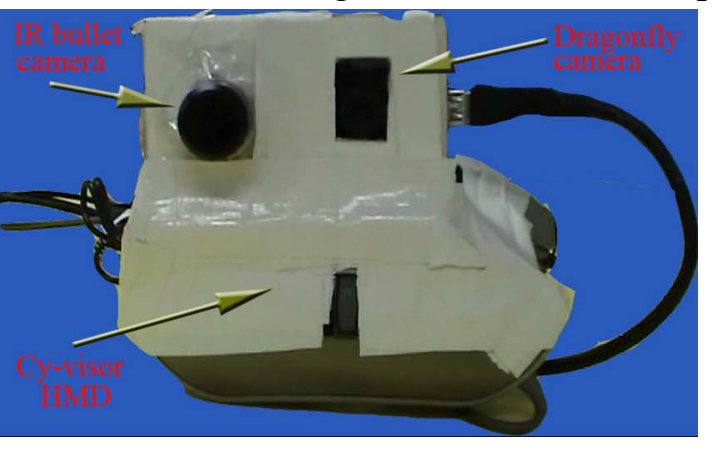

c)

Figure 1. a) DragonFly Camera. b) IR Bullet Camera. c) Capture and visualization system (Dragonfly camera, IR camera, and the HMD)

\subsection{Software}

The functionality of IMARS is the same as VMARS. Therefore, in this paper, we only comment on its functionalities briefly. The therapist/person in charge of the experiment can select the number of animals to appear: one animal, increase/reduce by three animals, or increase/reduce by 20 animals. The size of the animal/s can be increased/reduced. The animals can move or stop. It is possible to kill animals using two different elements (a can of insecticide and a flyswatter). When this occurs, the system plays a sound that is related to the tool used and one or more dead animals appear. If the spider 
is used, it is possible to choose among three types of spiders. A detailed description of the functionality of VMARS can be found in Juan et al.(2005).

To develop the two systems, we used the ARToolKit library (Kato \& Billinghurst, 1999) version 2.65 with virtual reality modeling language (VRML). The three-dimensional models of the virtual elements were designed using Autodesk 3D Studio Max. These models were exported to VRML format and edited with VRMLPad. Textures were created in Adobe Photoshop. VMARS and IMARS incorporated three different spiders and one cockroach. For each type of animal, three models were designed: a non-moving, a moving, and a dead animal. The non-moving animals are shown in static scenes, that is, when the animals are still. The moving model, that is, the model that includes the animation of the animal, is shown when the moving option has been selected. The dead animal appears when the user has killed one or several animals. To obtain a result as real as possible, the moving cockroach is animated with moving legs and moving antennae, and the spiders move their legs. When the animals are killed, the system produces a sound similar to that of a real animal being killed. Both systems include two sounds: a squirting sound similar to the sound of a real can of insecticide; and a squishing sound similar to that of a real cockroach or spider being crushed.

The graphical user interface was created using the OpenGL Utility ToolKit (GLUT)-based user interface library (GLUI, 2010). Sound support is provided by the OpenAL sound library.

\subsection{Description of the invisible marker-tracking AR system}

The two cameras (the IR camera and the colour camera) concurrently capture the scene of the real world. The image captured by the IR camera is processed with ARToolKit. The position and orientation of the IR camera can be established with respect to the marker. Since the relationship between the IR camera and the colour camera is known, it is possible to determine the position and orientation of the invisible marker in the image of the colour camera. Therefore, the virtual element is superimposed over the place where the invisible marker is located. As a result, the user sees a scene where no markers exist, but the virtual element appears in the correct position and orientation. The augmented image is finally shown on the microdisplays of the HMD. Figure 2 shows the steps followed by IMARS.

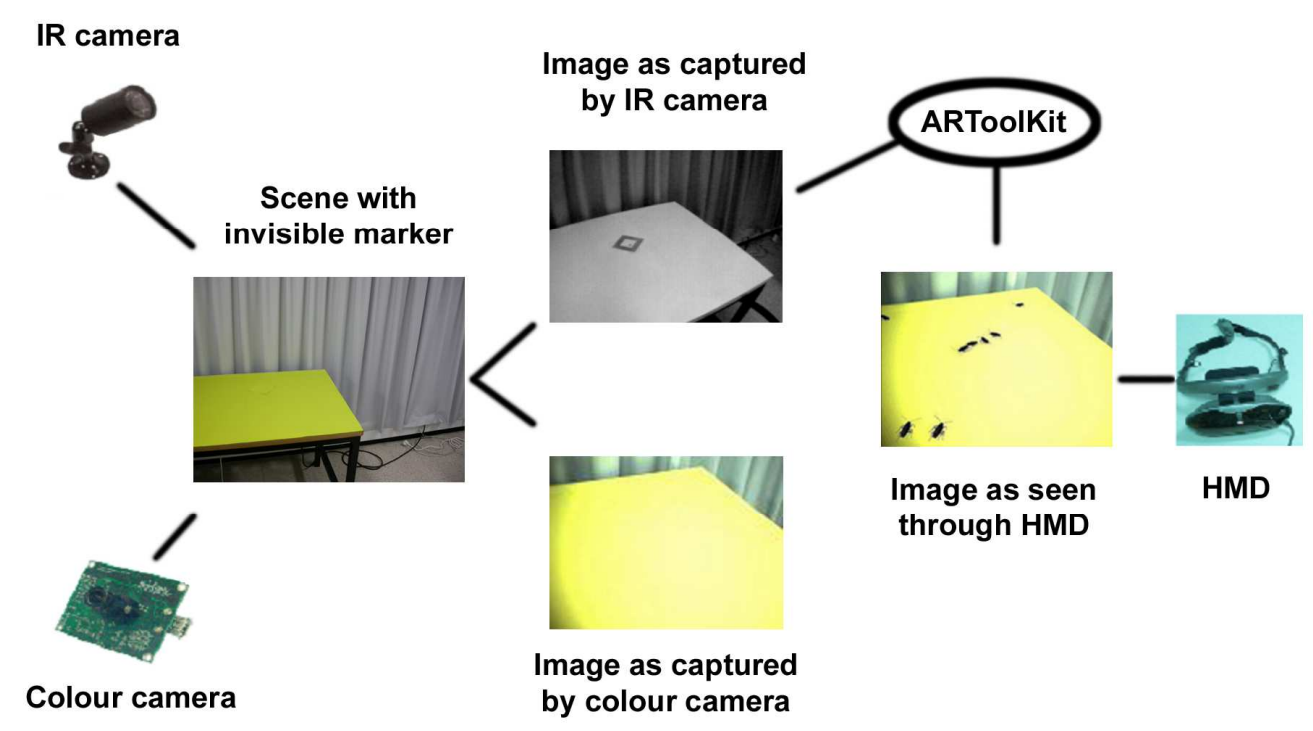

Figure 2. Steps followed by IMARS 
The physical volume in which users could look at the scene is the same as in VMARS because the volume that the user visualizes is captured by the colour camera and is the same in both systems. VMARS and IMARS have the same limitations. The appropriate distance from the user to the (visible or invisible) marker to work properly is the same. The tracking problems are also the same.

\section{Description of the study}

The aim of this study is to test if the IMARS induces a similar or higher sense of presence and provokes a similar or higher level of anxiety than the VMARS with non-phobic participants. For this purpose, subjective presence measurements collected after exposure to IMARS and VMARS were compared. For the level of anxiety, the participants were asked to rate their anxiety level at 8 different moments.

\section{Participants}

Twenty-five participants took part in the study (19 males, 6 females). The average age of the 25 participants was 25.96 years (S.D., 4.33). One male was excluded from the study because he had a fear score of more than 97 (on a scale from 0 to 126; Szymanski \& O'Donohue, 1995). Participants were recruited by advertisements on the University campus. All of them were students, scholars, or employees at the Technical University of Valencia. The participants did not receive any compensation for their time. All the participants filled out the fear and avoidance of cockroaches and spiders questionnaires (adapted from the Szymanski \& O'Donohue, (1995) questionnaire). Szymanski \& O'Donohue's questionnaire is intended for spiders, and we have also used it for cockroaches. The questionnaire has 18 items rated on a scale from 1 to $7(1=$ does not apply to me, $7=$ very much applies to me) about fear and avoidance regarding spiders/cockroaches. We have chosen Szymanski \& O'Donohue's questionnaire as other works have done (e.g. Garcia, 2002). Nevertheless, there are several measures for assessing spider phobia including the Spider Questionnaire (SPQ; Klorman et al., 1974), the Watts and Sharrock Spider Phobia Questionnaire (WS-SPQ; Watts \& Sharrock, 1984), or the Spider Phobia Beliefs Questionnaire (SBQ; Arntz et al, 1993). If participants had more phobia to spiders, they were exposed to the spider AR system $(\mathrm{N}=10)$; otherwise, they were exposed to the cockroach AR system $(\mathrm{N}=14)$. The range for this fear score was from 0 to 123 . The participant with a score of 123 was later excluded as an outlier (as explained in the next section); the next highest score was 82 . The mean score, excluding the outlier, was 25.5 .

\section{$\underline{\text { Procedure }}$}

Participants were counterbalanced and randomly assigned to one of two conditions:

a) Participants who used IMARS first and then VMARS.

b) Participants who used VMARS first and then IMARS.

Our initial idea was to divide the participants of the two groups into two subgroups: participants with a fear score of more than 97 (the clinical group, i.e., phobic people) and participants with a fear score of less than or equal to 97 (the normal group, i.e., non-phobic people). This value (97) is normally used as the cut-off for distinguishing phobic people from non-phobic people (e.g. in Garcia et al., 2002). Only one participant had a fear score of more than 97 . His fear score was 123 , and he was excluded from this study. After the test, the fear scores were analyzed to determine the value that divided participants into two subgroups (participants having less fear and participants with higher fear levels). The value for determining these two groups (less fear and higher fear levels) was 30 . This value was chosen due to the distribution of the participants. The fear mean (SD) was 11.7(9.7) for the group with less fear and 57.1(17.0) for the group with higher fear levels. 
The protocol was the following.

1) The participant came into the room where the study took place (for example, see Figure 3.a). For standardization across subjects, the scenario and interactivity were the same. In the room, the furniture used was a table and a chair. The participant always sat in a chair in front of the table (for example, see Figure 3.a). The marker was always placed on the table.

2) Before the participant was exposed to IMARS or VMARS, s/he received instructions about how to interact with the system during the experiment. Before the experience in VMARS, the participants were advised to look at the marker that was on the table. They were also advised not to occlude the marker. They were advised by the person conducting the experiment to move their hand when they were occluding the marker. Before the experience, for IMARS, the participants were advised to look in the direction of the table and to look for animals. They were also advised by the person conducting the experiment to move their hand when they were occluding the marker. For IMARS, since the participant had to look for the animals, if after some time the participant did not look in the right place (where the marker was placed), the person in charge of the experiment indicated the right direction to look in. The lighting conditions were the same throughout the entire experiment.

3) After these instructions, a narrative was introduced to him/her. We introduced this narrative in an attempt to add meaning to the experience for the participants. We had to keep in mind that the participants were non-phobic, and, therefore, we used the narrative to try and raise their interest in the experience and to encourage them to look carefully. The narrative was: "The city council has communicated that there is a plague of spiders/cockroaches in this area. They are planning a general disinfection, but before this disinfection, they need to analyze the situation and have asked the University to collaborate. The University has given you the responsibility of carrying out this task. You have to concentrate and look for any spiders/cockroaches, especially under the objects that are in this room. If you find animals, you will have to kill them, pick them up, and throw them away. You have to pay a lot of attention because later you have to report back to the University person in charge".

4) The participants used each system for about eight minutes. In both systems, the behaviour of the systems and the interaction of the participants were the same. All the interactions with the computer were performed by the person in charge of the experiment. Throughout all the experiment, the participants only had to look at the animal or animals (except for steps 7 to 10). The steps were the following.

1. An animal appeared over the marker (visible or invisible).

2. The animal started to move.

3. Three animals appeared.

4. The three animals started to move.

5. Twenty animals appeared.

6. The twenty animals started to move.

7. The participant put his/her hand on the table and the animals crossed over it (Figure 3.a shows a participant putting her hand on the table and the cockroaches crossing over it).

8. Only one animal was selected by the person in charge of the experiment. The participant was encouraged to look at the animal closely (even pick up the marker). The size of the animal was increased/reduced (Figures 4 and 5 show a participant looking at one animal closely using IMARS and VMARS, respectively).

9. The participant had to look for hidden animals. For this step, three boxes were placed on the table and the participant had to pick up these boxes to find the hidden animal (Figure 3.b and Figure 6 show two participants searching for hidden cockroaches). 
10. The participant had to kill an animal using a can of insecticide or a flyswatter (Figure 5.a shows the flyswatter used and Figure 7 shows a participant when he is killing a cockroach using the can of insecticide).

5) For the level of anxiety, the participants were asked to rate their own anxiety level (scores from $0=$ not anxious at all, to $10=$ very anxious) at 8 different moments during the AR experience. The moments and the order in which the anxiety level was asked were: P1-Before starting the experiment; P2-When the first animal appeared; P3-When three animals appeared; P4-When twenty animals appeared; P5-When participants put their hand on the table and animals crossed over it; P6-When participants were searching for hidden animals; P7-When participants killed animals; and P8-At the end of the exposure.

6) After using each system (IMARS or VMARS), the participants were asked to fill out an adapted Slater et al. questionnaire (SUS; Slater, Usoh \& Steed, 1994). SUS is a self-reporting questionnaire that is based on several questions which are all variations on one of three themes: the sense of being in the virtual environment, the extent to which the virtual environment becomes the dominant reality, and the extent to which the virtual environment is remembered as a 'place'. The SUS questionnaire has six questions, each of which uses a scale from 1 to 7 with the higher score indicating greater presence. Our adaptation modified the three themes as: the sense of being in a room where there are cockroaches/spiders; the extent to which the cockroaches/spiders were real; and the extent to which the AR experience is remembered as a 'place where there were cockroaches/spiders'. However, self-reporting is known to have a number of limitations. First, the questionnaires only offer a subject's impression of presence post-experience, which can be misleading. Second, since the experimenter is asking the subject to verbalize his/her level of presence, this could have an impact on his/her sense of presence. We have chosen SUS because of its popularity for facilitating comparisons with other studies. However, there are several other questionnaires available (e.g. ITC-SOPI; Lessiter et al., 2001), even physiological measures (Meehan et al., 2002) or methods in which the measure depends on the data collected during the experience (Slater \& Steed, 2000, in which the number of transitions from virtual to real is counted, and a probabilistic Markov chain model can be constructed to model these transitions). In our study, the 6 questions related to the sense of presence were as follows. The scoring was on a scale from 1 to 7. Q1-Please rate your sense of being in a room where there are cockroaches/spiders (where 7 represents your normal experience of being in a place); Q2-To what extent were there times during the experiment when the cockroaches/spiders were real for you?; Q3-When you think back to your experience, do you think of cockroaches/spiders more as images that you saw (a movie, a picture), or more as cockroaches/spiders that were in the same room as you were?; Q4-During the experiment, which was strongest on the whole: your sense of being in the room where there were cockroaches, or your sense of being in a room without cockroaches/spiders?; Q5-Think about your memory of being in "a room where there were cockroaches/spiders". How similar is this memory to your memories of other places where there were these animals?; Q6-During the experiment, did you often think that you were actually in a room where there were cockroaches/spiders?. The participants filled out this questionnaire twice, after using VMARS and after using IMARS.

7) After using the two systems, the participants were asked to fill out a final questionnaire. This questionnaire had six questions. Four questions related to the animals. F1-What is the maximum number of animals you have seen using the systems?. F2-How many animals did you interact with?. F3-How many legs did the animals you saw have?. F4-What colour were the animals you saw?. F5-Add any comment. F6-Did you have the same sensations and surprises with the two systems? If the answer is no, please, rate this difference from 1 to 10 indicating how much you improved your sensations/surprise with IMARS over VMARS. 


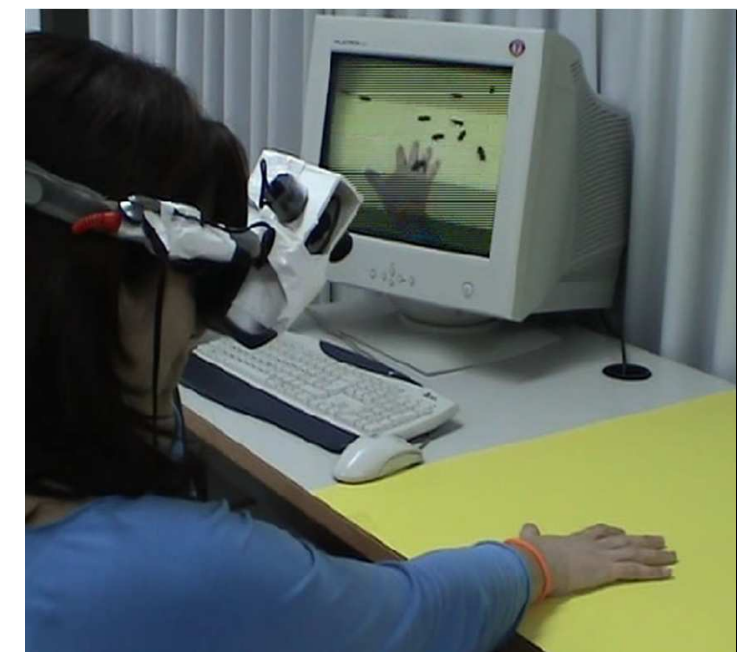

a)

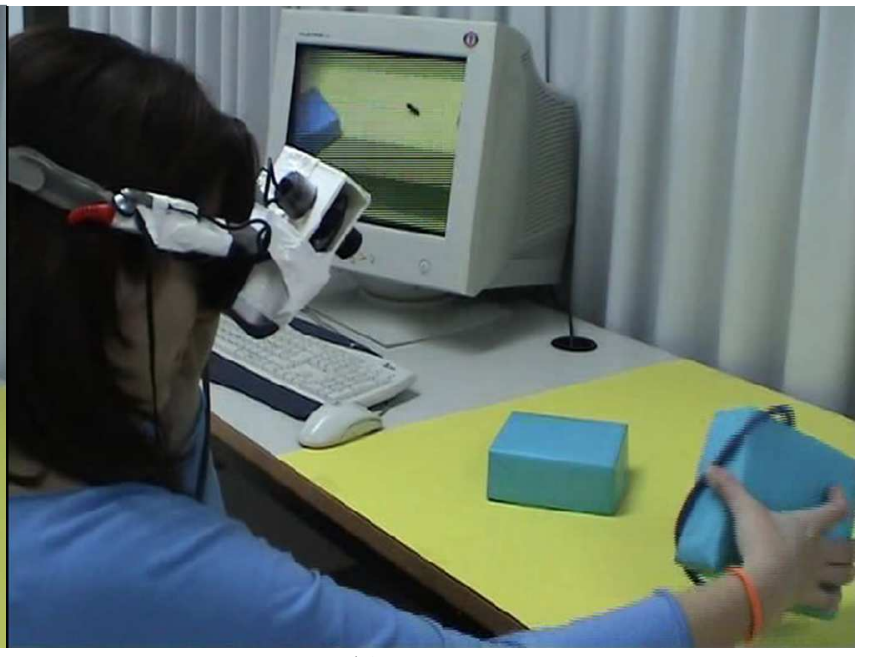

b)

Figure 3. Two moments during the experiment of a participant using IMARS. a) Participant putting her hand on the table and the cockroaches crossing over it. b) Participant searching for hidden cockroaches

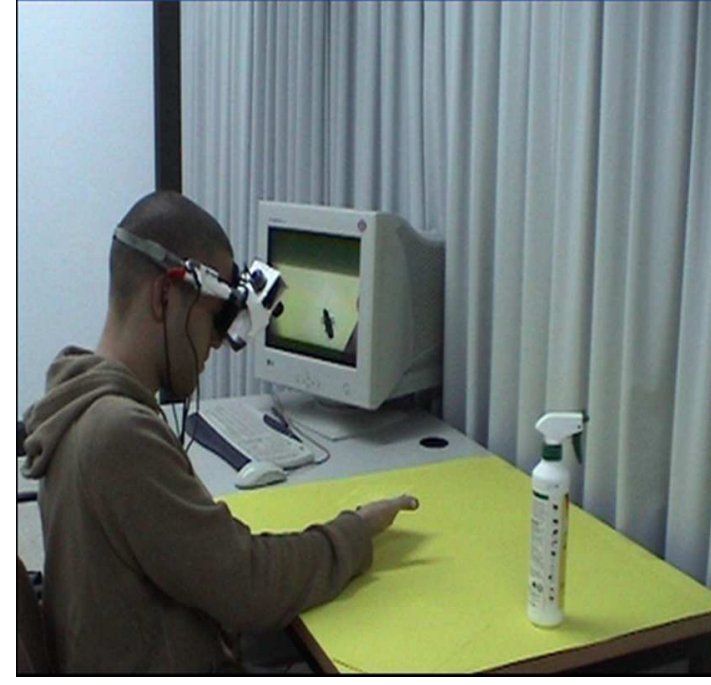

a)

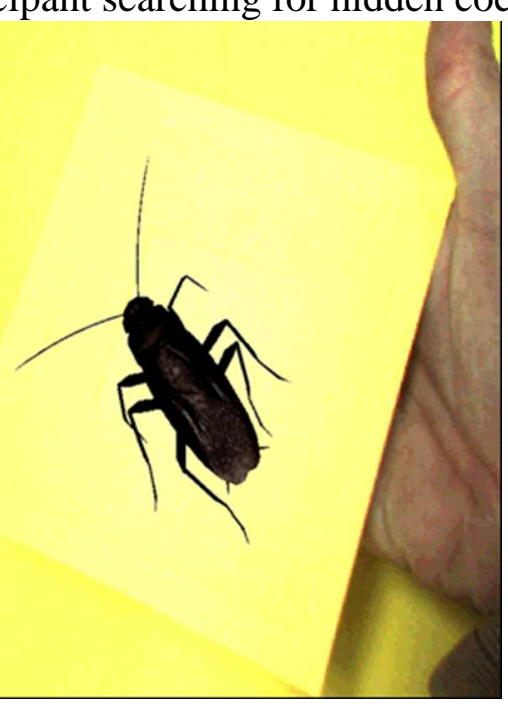

b)

Figure 4. Participant using IMARS. He is looking at one animal closely

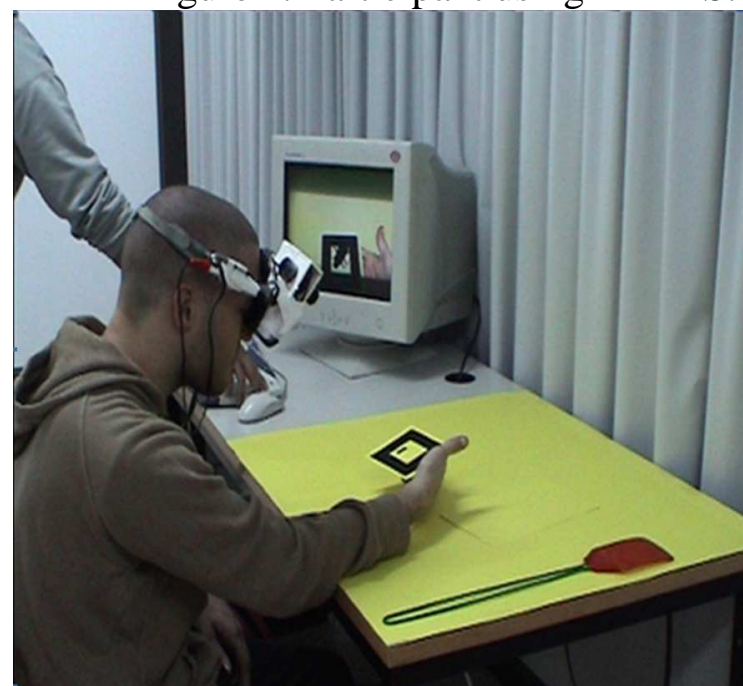

a)

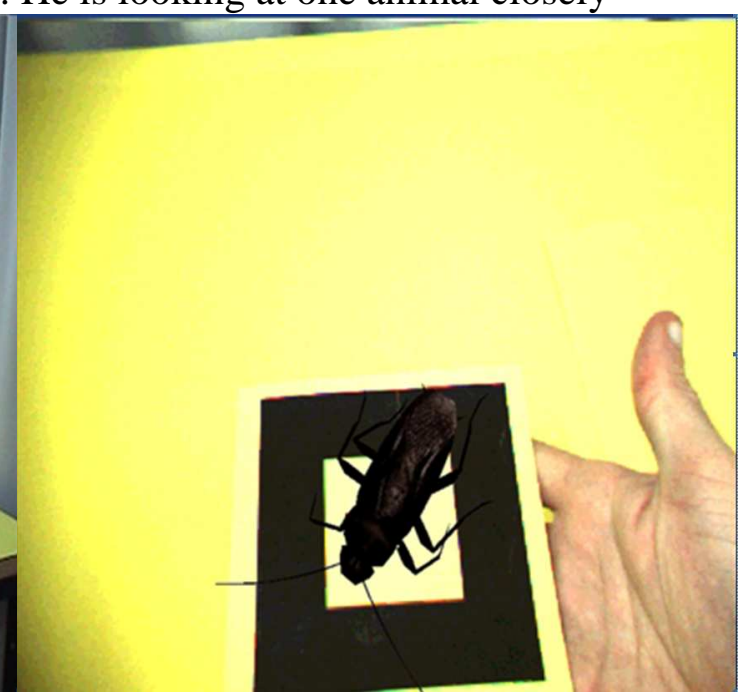

b)

Figure 5. Participant using VMARS. He is looking at one animal closely 


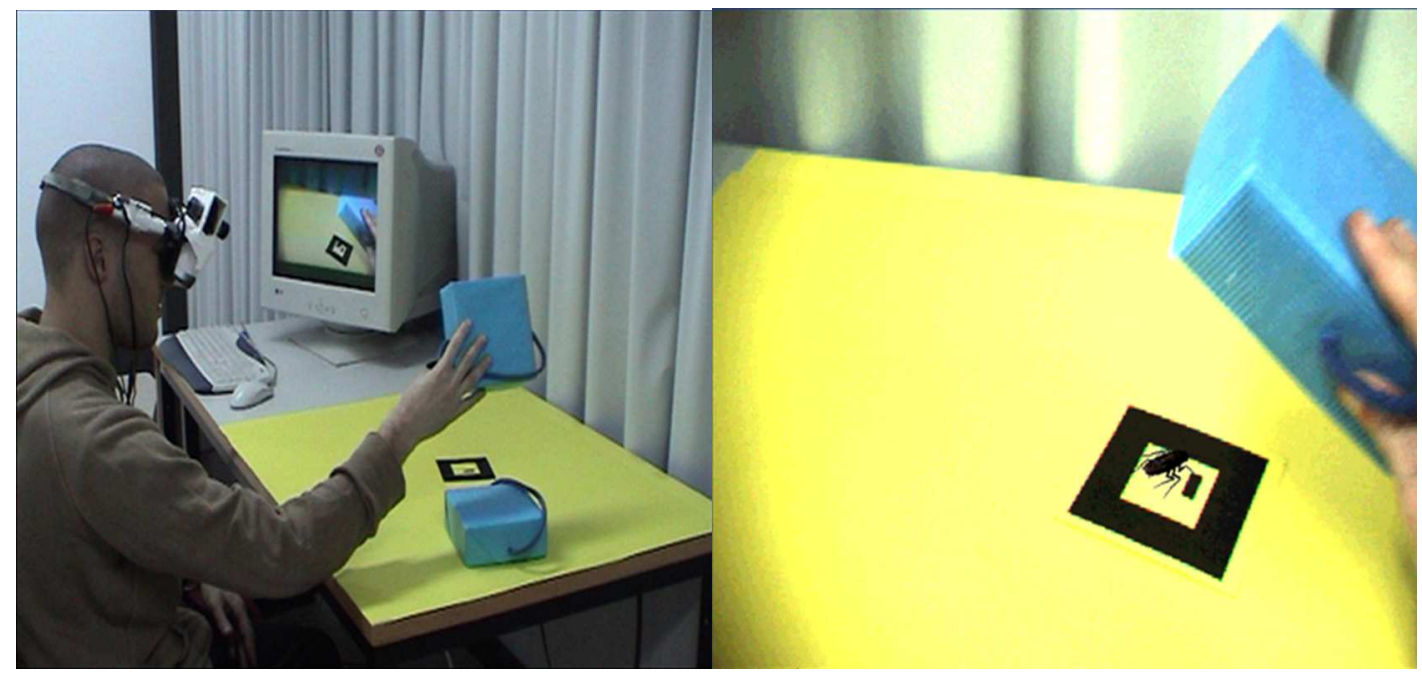

a)

b)

Figure 6. Participant using VMARS. He is searching for hidden cockroaches

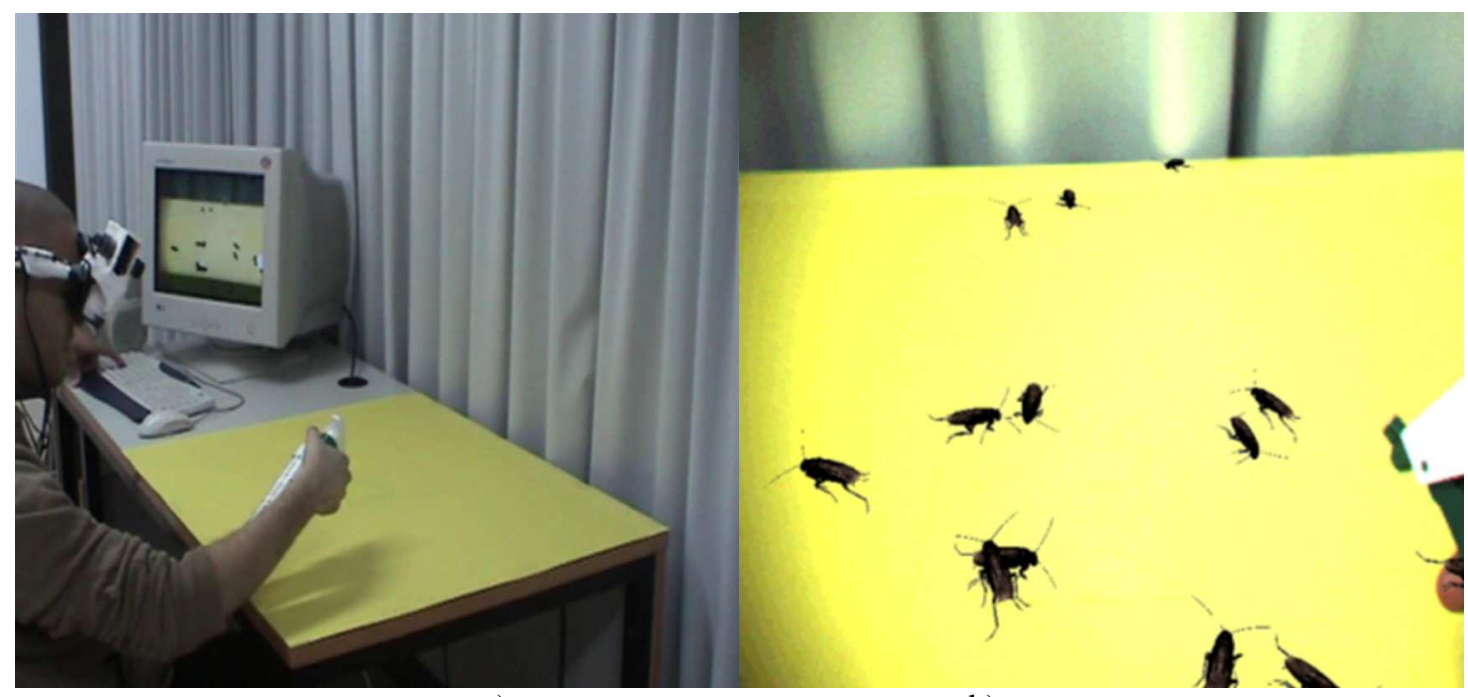

a)

b)

Figure 7.a) Participant using IMARS. b) View of the participant when he is killing cockroaches using the can of insecticide

\section{Results}

For the sense of presence, Table 1 shows the results related to presence measures. All the participants were considered. Paired t-tests were applied to the scores given to all of the questions. The Mean column uses the mean score across the 6 questions. The remaining columns show the mean results for the individual questions. The significance level was set to 0.05 in all tests. The results from questions Q1-Q2 showed statistically significant differences between the two systems when tests were applied. These results indicate that the participants considered the IMARS system to be clearly different and that it induced a higher sense of presence than the VMARS system. The results from questions Q3-Q6 showed no statistically significant differences, but the means for the IMARS system were higher. Thus, for questions Q3-Q6, participants perceived a similar sense of presence when using the two systems. From these results, we can deduce that both systems induced a similar sense of presence for Q3-Q6 and a higher sense of presence for Q1-Q2. Therefore, IMARS induced a similar or higher sense of presence than VMARS. In order to determine whether using one of the two systems first has some effect on the presence measurement for the second system, the sample was divided into two groups (the participants who used IMARS first and the participants who used VMARS first). Student $t$ tests assuming equal variances were applied to the scores given to all questions. The sample 
was also divided into two groups (the participants who had less fear than $30, \mathrm{~N}=16$, and the participants who had higher fear levels than $30, \mathrm{~N}=8$ ). In this analysis, no statistically significant differences were found (see Tables 2-5). This indicates that the order in which the participants used the systems did not influence their presence scores. To sum up, IMARS induced a similar or higher sense of presence than VMARS and the order of exposure did not change the results.

\begin{tabular}{|l|l|l|l|l|l|l|l|}
\hline & Mean & Q1 & Q2 & Q3 & Q4 & Q5 & Q6 \\
\hline IMARS & $3.83 \pm 1.80$ & $4.08 \pm 1.72$ & $4.00 \pm 1.79$ & $3.67 \pm 1.74$ & $3.83 \pm 1.86$ & $3.75 \pm 1.90$ & $3.67 \pm 1.95$ \\
\hline VMARS & $3.48 \pm 1.77$ & $3.58 \pm 1.69$ & $3.63 \pm 1.81$ & $3.25 \pm 1.62$ & $3.58 \pm 1.72$ & $3.46 \pm 1.96$ & $3.38 \pm 1.93$ \\
\hline $\mathrm{t}$ & & $3.39^{* *}$ & $2.10^{* *}$ & 1.45 & 1.45 & 0.92 & 1.57 \\
\hline $\mathrm{p}$ & & $0.003^{* *}$ & $0.047^{* *}$ & 0.162 & 0.162 & 0.365 & 0.129 \\
\hline
\end{tabular}

Table 1. Means and standard deviations of IMARS and VMARS and paired t-tests for presence scores; d.f. 23 ; ' $* *$ ' indicates statistically significant differences.

\begin{tabular}{|l|l|l|l|l|l|l|}
\hline & $\mathrm{Q} 1$ & $\mathrm{Q} 2$ & $\mathrm{Q} 3$ & $\mathrm{Q} 4$ & $\mathrm{Q} 5$ & $\mathrm{Q} 6$ \\
\hline IMARS First & $3.25 \pm 1.58$ & $3.38 \pm 1.85$ & $3.38 \pm 1.92$ & $3.25 \pm 1.83$ & $3.00 \pm 2.14$ & $3.13 \pm 2.03$ \\
\hline IMARS Second & $3.88 \pm 1.25$ & $3.63 \pm 1.85$ & $3.25 \pm 1.39$ & $3.25 \pm 1.67$ & $3.38 \pm 1.51$ & $2.88 \pm 1.46$ \\
\hline $\mathrm{t}$ & -0.88 & -0.27 & 0.15 & 0.00 & -0.41 & 0.28 \\
\hline $\mathrm{p}$ & 0.395 & 0.791 & 0.884 & 1.000 & 0.691 & 0.781 \\
\hline
\end{tabular}

Table 2. Means and standard deviations of IMARS used first and second and student $t$ tests assuming equal variances for presence scores for participants whose fear was less than 30; d.f. 14.

\begin{tabular}{|l|l|l|l|l|l|l|}
\hline & $\mathrm{Q} 1$ & $\mathrm{Q} 2$ & $\mathrm{Q} 3$ & $\mathrm{Q} 4$ & $\mathrm{Q} 5$ & $\mathrm{Q} 6$ \\
\hline VMARS First & $3.38 \pm 1.19$ & $2.88 \pm 1.46$ & $3.25 \pm 1.28$ & $3.25 \pm 1.49$ & $3.38 \pm 1.30$ & $2.38 \pm 1.30$ \\
\hline VMARS Second & $3.00 \pm 1.85$ & $3.63 \pm 2.00$ & $3.13 \pm 2.10$ & $3.00 \pm 1.85$ & $3.25 \pm 2.55$ & $3.38 \pm 2.20$ \\
\hline $\mathrm{t}$ & 0.48 & -0.86 & 0.14 & 0.30 & 0.12 & -1.11 \\
\hline $\mathrm{p}$ & 0.637 & 0.405 & 0.888 & 0.770 & 0.904 & 0.287 \\
\hline
\end{tabular}

Table 3. Means and standard deviations of VMARS used first and second and student t tests assuming equal variances for presence scores for participants whose fear was less than 30; d.f. 14.

\begin{tabular}{|l|l|l|l|l|l|l|}
\hline & $\mathrm{Q} 1$ & $\mathrm{Q} 2$ & $\mathrm{Q} 3$ & $\mathrm{Q} 4$ & $\mathrm{Q} 5$ & $\mathrm{Q} 6$ \\
\hline IMARS First & $4.50 \pm 1.00$ & $4.50 \pm 1.00$ & $3.50 \pm 1.00$ & $4.50 \pm 0.58$ & $4.75 \pm 1.26$ & $4.00 \pm 0.82$ \\
\hline IMARS Second & $5.75 \pm 2.50$ & $5.50 \pm 1.73$ & $5.25 \pm 2.22$ & $5.50 \pm 2.38$ & $5.00 \pm 2.16$ & $6.00 \pm 2.00$ \\
\hline $\mathrm{t}$ & -0.93 & -1.00 & -1.44 & -0.82 & -0.2 & -1.85 \\
\hline $\mathrm{p}$ & 0.389 & 0.356 & 0.200 & 0.445 & 0.848 & 0.114 \\
\hline
\end{tabular}

Table 4. Means and standard deviations of IMARS used first and second and student t tests assuming equal variances for presence scores for participants whose fear was more than 30; d.f. 6 .

\begin{tabular}{|l|l|l|l|l|l|l|}
\hline & Q1 & Q2 & Q3 & Q4 & Q5 & Q6 \\
\hline VMARS First & $5.00 \pm 2.16$ & $5.25 \pm 2.22$ & $3.50 \pm 2.38$ & $4.75 \pm 2.06$ & $4.75 \pm 2.22$ & $5.25 \pm 1.71$ \\
\hline VMARS Second & $3.75 \pm 1.50$ & $3.50 \pm 1.00$ & $3.25 \pm 0.50$ & $4.25 \pm 1.26$ & $2.75 \pm 1.50$ & $3.50 \pm 1.73$ \\
\hline $\mathrm{t}$ & 0.95 & 1.44 & 0.21 & 0.41 & 1.49 & 1.44 \\
\hline $\mathrm{p}$ & 0.379 & 0.200 & 0.844 & 0.693 & 0.186 & 0.200 \\
\hline
\end{tabular}

Table 5. Means and standard deviations of VMARS used first and second and student $t$ tests assuming equal variances for presence scores for participants whose fear was more than 30; d.f. 6; '**' indicates statistically significant differences.

For anxiety levels, we distinguished between the two groups, subjects having less fear $(\mathrm{N}=16)$ and subjects with higher fear levels $(\mathrm{N}=8)$. The anxiety values were collected during the exposure at moments P1-P8. Table 6 shows paired t-tests for the scores given in response to anxiety questions for the two systems for all the participants. The significance level was set to 0.05 in all tests. The results from Table 6 show that there is only a statistically significant difference in the anxiety level in step 3, 
but the means for IMARS were higher in five of the eight questions. For step 3, the participants considered the IMARS system to be clearly different and provoked a higher level of anxiety than the VMARS system. The results from Q1-Q2 and Q4-Q8 showed no statistically significant differences. From these results, we can deduce that both systems induced a similar sense of anxiety for Q1-Q2 and Q4-Q8 and a higher sense of anxiety for Q3. Therefore, IMARS induced a similar or higher level of anxiety than VMARS.

We also compared the anxiety level at the moment before starting the experiment with the anxiety level during the different stages of the experiment using the two systems. The paired t-tests are shown in Tables 7-10. The results indicate that there is a statistically significant difference between the initial anxiety and the anxiety in later stages. In order to determine whether the participants with higher fear levels report more anxiety, the scores of this group have been analyzed, and paired t-tests were applied to the scores given to all questions (see Tables 9-10). The results are similar to those obtained when analyzing all the participants. That is, the results indicate that there is a statistically significant difference between the initial anxiety and the anxiety felt during the experiment in both systems. The only difference was for the participants who had higher fear levels; when they used the markertracking system for the second step (when the first animal appeared), the results did not report statistically significant differences. However, they did for other steps. To sum up, IMARS provoked a similar or higher level of anxiety than VMARS and the two systems both induced statistically significant anxiety during the experiments.

\begin{tabular}{|l|l|l|l|l|l|l|l|l|l|}
\hline & Mean & P1 & P2 & P3 & P4 & P5 & P6 & P7 & P8 \\
\hline IMARS & $1.96 \pm 2.44$ & $0.88 \pm 1.19$ & $1.54 \pm 1.84$ & $2.00 \pm 2.40$ & $2.79 \pm 2.78$ & $3.46 \pm 3.31$ & $2.29 \pm 2.73$ & $1.63 \pm 2.18$ & $1.50 \pm 2.34$ \\
\hline VMARS & $1.95 \pm 2.52$ & $0.83 \pm 1.40$ & $1.58 \pm 2.38$ & $1.71 \pm 2.26$ & $2.67 \pm 2.93$ & $3.13 \pm 3.11$ & $1.92 \pm 2.30$ & $1.83 \pm 2.44$ & $1.54 \pm 2.17$ \\
\hline $\mathrm{t}$ & & 0.30 & -0.15 & $2.60^{* *}$ & 0.72 & 1.62 & 1.68 & -1.16 & -0.24 \\
\hline $\mathrm{p}$ & & 0.770 & 0.883 & $0.016^{* *}$ & 0.479 & 0.119 & 0.107 & 0.260 & 0.814 \\
\hline
\end{tabular}

Table 6. Means and standard deviations of IMARS and VMARS and paired t-tests for anxiety levels; d.f. 23 ; ' $* *$ ' indicates statistically significant differences.

\begin{tabular}{|l|l|l|l|l|l|l|l|}
\hline & P2 & P3 & P4 & P5 & P6 & P7 & P8 \\
\hline Mean \pm S.D. & $1.54 \pm 1.84$ & $2.00 \pm 2.40$ & $2.79 \pm 2.78$ & $3.46 \pm 3.31$ & $2.29 \pm 2.73$ & $1.63 \pm 2.18$ & $1.50 \pm 2.34$ \\
\hline $\mathrm{t}$ & $-3.00^{* *}$ & $-3.34^{* *}$ & $-4.65^{* *}$ & $-4.96^{* *}$ & $-3.74^{* *}$ & $-2.64^{* *}$ & -1.90 \\
\hline $\mathrm{p}$ & $0.007^{* *}$ & $0.003^{* *}$ & $<0.001^{* *}$ & $<0.001^{* *}$ & $<0.001^{* *}$ & $0.015^{* * *}$ & 0.070 \\
\hline
\end{tabular}

Table 7. Comparison of the initial level of anxiety with the level of anxiety in steps 2-8 of IMARS

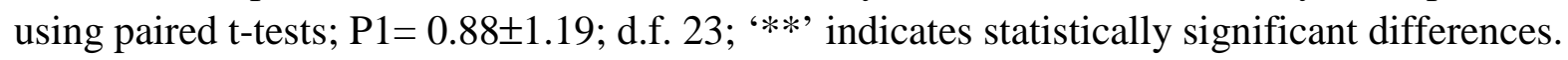

\begin{tabular}{|l|l|l|l|l|l|l|l|}
\hline & P2 & P3 & P4 & P5 & P6 & P7 & P8 \\
\hline Mean \pm S.D. & $1.58 \pm 2.38$ & $1.71 \pm 2.26$ & $2.67 \pm 2.93$ & $3.13 \pm 3.11$ & $1.92 \pm 2.30$ & $1.83 \pm 2.44$ & $1.54 \pm 2.17$ \\
\hline $\mathrm{t}$ & $-2.43^{* *}$ & $-3.31^{* *}$ & $-4.20^{* *}$ & $-4.78^{* *}$ & $-3.82^{* *}$ & $-2.89^{* *}$ & $-2.21^{* *}$ \\
\hline $\mathrm{p}$ & $0.023^{* *}$ & $0.003^{* *}$ & $<0.001^{* *}$ & $<0.001^{* *}$ & $0.001^{* *}$ & $0.008^{* *}$ & $0.038^{* *}$ \\
\hline
\end{tabular}

Table 8. Comparison of the initial level of anxiety with the level of anxiety in steps 2-8 of VMARS using paired t-test; $\mathrm{P} 1=0.83 \pm 1.40$; d.f. 23 ; ' $* *$ ' indicates statistically significant differences.

\begin{tabular}{|l|l|l|l|l|l|l|l|}
\hline & $\mathrm{P} 2$ & $\mathrm{P} 3$ & $\mathrm{P} 4$ & $\mathrm{P} 5$ & $\mathrm{P} 6$ & $\mathrm{P} 7$ & $\mathrm{P} 8$ \\
\hline Mean \pm S.D. & $3.50 \pm 1.77$ & $4.38 \pm 2.56$ & $5.63 \pm 2.72$ & $6.88 \pm 2.95$ & $5.25 \pm 2.55$ & $3.88 \pm 2.36$ & $3.88 \pm 2.75$ \\
\hline $\mathrm{t}$ & $-3.00^{* *}$ & $-3.15^{* *}$ & $-4.66^{* *}$ & $-5.85^{* *}$ & $-5.97^{* *}$ & $-2.71^{* *}$ & -2.25 \\
\hline $\mathrm{p}$ & $0.020^{* *}$ & $0.016^{* *}$ & $0.002^{* *}$ & $<0.001^{* *}$ & $0.002^{* *}$ & $0.030^{* *}$ & 0.059 \\
\hline
\end{tabular}

Table 9. Comparison of the initial level of anxiety with the level of anxiety in steps 2-8 of IMARS using paired t-test, and for the group of participants with higher fear levels; $\mathrm{P} 1=2.00 \pm 1.31$; d.f. 7 ; '**, indicates statistically significant differences. 


\begin{tabular}{|l|l|l|l|l|l|l|l|}
\hline & $\mathrm{P} 2$ & $\mathrm{P} 3$ & $\mathrm{P} 4$ & $\mathrm{P} 5$ & $\mathrm{P} 6$ & $\mathrm{P} 7$ & $\mathrm{P} 8$ \\
\hline Mean \pm S.D. & $3.63 \pm 3.25$ & $3.88 \pm 2.70$ & $5.50 \pm 3.25$ & $6.25 \pm 2.97$ & $4.38 \pm 2.26$ & $4.13 \pm 2.85$ & $3.38 \pm 2.83$ \\
\hline $\mathrm{t}$ & -2.20 & $-3.74^{* *}$ & $-4.30^{* *}$ & $-6.20^{* *}$ & $-4.77^{* *}$ & $-2.91^{* *}$ & -1.82 \\
\hline $\mathrm{p}$ & 0.064 & $0.007^{* *}$ & $0.004^{* *}$ & $<0.001^{* *}$ & $<0.001^{* *}$ & $0.023^{* *}$ & 0.111 \\
\hline
\end{tabular}

Table 10. Comparison of the initial level of anxiety with the level of anxiety in steps 2-8 of VMARS using paired t-test, and for the group of participants with higher fear levels; $\mathrm{P} 1=1.88 \pm 1.88$; d.f. 7 ; '**' indicates statistically significant differences.

For explicit preference (F6-Did you have the same sensations and surprise with the two systems?), the percentage of participants who answered yes was $16.67 \%$. That is, they did not find any difference between the two systems. The rest of the participants (83.33\%) answered no. This second group of participants scored the improved sensations and surprise with IMARS over VMARS as 5.19 \pm 2.25 (on a scale from 1 to 10). The values for the group with higher fear levels were: all participants (100\%) answered no, and they scored IMARS better as $6.38 \pm 1.60$.

\section{Conclusions}

We have presented the first IMARS for the treatment of a phobia towards small animals. In this work, we have carried out a study with twenty-four non-phobic participants, and we have compared the visible marker-tracking and the invisible marker-tracking systems. The results indicate that IMARS induces a similar or higher sense of presence, and it also provokes a similar or higher anxiety level in important steps for therapy. Moreover, $83.33 \%$ of the total participants reported that they did not have the same sensations/surprise using the two systems, and they scored the advantage of using IMARS at $5.19 \pm 2.25$ (on a scale from 1 to 10 ). However, if only the group with higher fear levels is considered, $100 \%$ of the participants reported that they did not have the same sensations/surprise with the two systems, scoring the advantage of using IMARS at $6.38 \pm 1.60$ (on a scale from 1 to 10 ). Since VMARS has already been successfully used for treatment with real patients (Juan et al., 2005; Botella et al., 2005), and since IMARS induces a similar or higher sense of presence and also provokes similar or higher anxiety, we believe that IMARS could also be a useful tool for treatment. However, future studies should corroborate whether or not IMARS is a suitable tool for treatment and whether there are any differences in treatment using IMARS and VMARS. The main drawback of this study is the number of participants in each group, especially in the subgroup of participants who had higher fear levels, which had only eight participants. A new study with a larger sample would be required in order to assure high practical significance. Another drawback of our study is the impossibility of establishing correlations between presence and anxiety. This is due to the fact that these two measures were asked for at different moments. This could be solved by asking for presence scores and anxiety levels at the same time.

In visible-marker-tracking systems, users relate the marker with the appearance of virtual elements. Instead of using these visible-marker-tracking systems, a more natural, less obtrusive, and more surprising systems without markers could be developed (e.g. using Studierstube Tracker rather than ARToolKit). Moreover, markerless techniques such as those described in section 2.3 could also be used for developing a similar system to IMARS. The two systems, IMARS and VMARS, have the problems associated with marker tracking: fast movements or changing light conditions cause tracking to fail, the entire marker must be in view for tracking to work, the problem of occluding the marker, etc. In this work, we have not evaluated these interface issues. Taking these interface issues into account, the two systems could be improved by adding cues to the interface in order to alert the user when the marker tracking is failing or about to fail (Xu et al., 2008).

With regard to other future works, first, presence is a subjective condition and the use of selfreports could give rise to some errors if the user does not give the correct score. As mentioned in 
subsection 3.1, it is possible to use physiological measures to measure presence (Meehan et al., 2002), for example, using galvanic skin response (GSR). Several studies have investigated the effect of GSR for the treatment of phobias and shock (e.g. for fear of flying (Wiederhold et al., 2002)). It is also possible to use methods in which the measure depends on the data collected during the experience (Slater \& Steed, 2000). One possible future study would be to incorporate these measures and contrast the results with the ones obtained with questionnaire responses.

Finally, IMARS and VMARS have the same functionality and performance. As an invisible marker-tracking system, IMARS has two advantages: the user does not see any intruding element in the scene; and the fusion of the virtual objects with the real scene is totally natural. These advantages can be useful not only for psychological applications, but also for any application in which the nonappearance of the marker is important such as applications for art exhibitions or publicity.

\section{Acknowledgements:}

We would like to thank:

- Cristina Botella, Rosa Baños, and Charles van der Mast for their help.

- LabHuman for letting us use the hardware for developing and testing the systems.

\section{References}

APA (American Psychiatric Association), 2000. Diagnostic and statistical manual of mental disorders. ( $4^{\text {th }}$, Text Revision ed.). Arlington, VA: American Psychiatric Association

Armstrong, M. \& Zisserman, A., 1995. Robust object tracking. The Asian Conference on Computer Vision, pp. 58-62.

Arntz, A., Lavy, E., van den Berg, G. \& van Rijsoort, S., 1993. Negative beliefs of spider phobics: A psychometric evaluation of the Spider Phobia Beliefs Questionnaire. Advances in Behaviour Research and Therapy, 15: 257-277.

Basu, S., Essa, I. \& Pentland, A., 1996. Motion regularization for model-based head tracking. The International Conference on Pattern Recognition, 7276: 611.

Botella , C., Baños, R., Quero, S., Perpiña, C. \& Fabregat, S., 2004. TelePsychology and Self-Help: The treatment of phobias using the Internet, Cybertherapy, CD-ROM.

Botella, C., Juan, M.C., Baños, R.M., Alcañiz, M., Guillen, V. \& Rey, B., 2005. Mixing realities? An Application of augmented reality for the treatment of cockroach phobia. CyberPsychology \& Behavior, 8: 162-171.

Bouchard, S., St-Jaques, J., Robillard, G. \& Renaud, P., 2008. Anxiety increases the feeling of presence in virtual reality, Presence: Teleoperators and Virtual Environments, 17(4):376-390.

Bowman, D.A., Kruijff, E., LaViola, J.J. \& Poupyrev, I., 2005. User Interfaces. Theory and practice, Ed. Addison-Wesley.

Carlin, A., Hoffman, H. \& Weghorst, S., 1997. Virtual reality and tactile augmentation in the treatment of spider phobia: a case study, Behaviour Research and Therapy, 35(2): 153-158.

Cascia, M., Sclaroff, S. \& Athitsos, V., 2000. Fast, reliable head tracking under varying illumination: An approach based on registration of texture-mapped 3D models. IEEE Transactions on Pattern Analysis and Machine Intelligence, 22(4): 322-336.

Cawood, S. \& Fiala, M. (2007). Augmented Reality: A practical guide, Pragmatic Bookshelf, North Carolina Dallas, Texas

Comport, A. I., Marchand, E. \& Chaumette, F., 2003. A real-time tracker for markerless augmented reality. The International Symposium on Mixed and Augmented Reality, pp. 36-45. 
Cho, Y., Lee, W. J. \& Neumann, U., 1998. A multi-ring color fiducial system and intensity-invariant detection method for scalable fiducial-tracking augmented reality. International Workshop on Augmented Reality.

Claus, D. \& Fitzgibbon, A., 2004. Reliable fiducial detection in natural scenes. European Conference on Computer Vision. 3024: 469-480.

DeCarlo, D. \& Metaxas, D., 2000. Optical flow constraints on deformable models with applications to face tracking. International Journal of Computer Vision, 38: 99-127.

Drummond, T. \& Cipolla, R., 2002. Real-time visual tracking of complex structures. IEEE Transactions on Pattern Analysis and Machine Intelligence, 27(7): 932-946.

Fua, P. \& Lepetit, V., 2007. Vision based 3D tracking and pose estimation for mixed reality, Chapter 1, Emerging Technologies of augmented reality. Interfaces and design, Ed. Idea Group Publishing, Editors: Haller, M., Billinghurst, M. Thomas, B.

Garcia-Palacios, A., Hoffman, H. G., Carlin, A., Furness, T. \& Botella, C., 2002. Virtual reality in the treatment of spider phobia: A controlled study. Behaviour Research and Therapy, 9: 983-993.

GLUI, 2010. GLUI User Interface Library, version 2.35, Available online at <http://glui.sourceforge.net>, (last accessed: 27 July 2010).

Hager, G. D. \& Belhumeur, P. N., 1998. Efficient region tracking with parametric models of geometry and illumination. IEEE Transactions on Pattern Analysis and Machine Intelligence, 20(10): 10251039.

Harris, C., 1992. Tracking with rigid objects. MIT Press.

Heeter, C., 1992. Being There: The subjective experience of presence. Presence: Teleoperators \& Virtual Environments, 1(2), 262-271.

Hoff, W. A., Nguyen, K. \& Lyon, T., 1996. Computer vision-based registration techniques for augmented reality. Intelligent Robots and Control Systems XV, Intelligent Control Systems and Advanced Manufacturing, pp. 538-548.

Juan, M.C., Alcañiz, M., Monserrat, C., Botella, C., Baños, R. \& Guerrero, B., 2005. Using augmented reality to treat phobias, IEEE Computer Graphics and Applications, 25(6): 31-37.

Juan, M.C., Baños, R., Botella, C., Perez, D., Alcañiz, M. \& Monserrat, C., 2006. An augmented reality system for acrophobia: The sense of presence using immersive photography, Presence: Teleoperators \& Virtual Environments, 15: 393-402.

Jurie, F. \& Dhome, M., 2001. A simple and efficient template matching algorithm. The International Conference on Computer Vision, 2: 544-549.

Jurie, F. \& Dhome, M., 2002. Hyperplane approximation for template matching. IEEE Transactions on Pattern Analysis and Machine Intelligence, 24(7): 996-100.

Kato, H. \& Billinghurst, M., 1999. Marker tracking and HMD calibration for a video-based augmented reality conferencing system. IEEE and ACM International Workshop on Augmented Reality, pp. 85-94, Available online at <http://www.hitl.washington.edu/artoolkit>, (last accessed: 27 July 2010).

Klorman, R., Hastings, J.E., Weerts, T.C., Melamed, B.G. \& Lang, P.J., 1974. Psychometric description of some specific-fear questionnaires. Behavior Therapy, 5: 401-409.

Koller, D., Klinker, G., Rose, E., Breen, D. E., Whitaker, R. T. \& Tuceryan, M., 1997. Real-time Vision-based camera tracking for augmented reality applications. ACM Symposium on Virtual Reality Software and Technology, pp. 87-94.

Lessiter, J., Freeman, J., Keogh, E. \& Davidoff, J., 2001. A cross-media presence questionnaire: The ITC sense of presence inventory. Presence: Teleoperators and Virtual Environments, 10(3): 282297.

Li, H., Roivainen, P. \& Forchheimer, R., 1993. 3D motion estimation in model-based facial image coding. IEEE Transactions on Pattern Analysis and Machine Intelligence, 15(6): 545-555. 
Looser, J. (2007). AR Magic Lenses: Addressing the challenge of focus and context in augmented reality, Doctoral Dissertation, Computer Science and Software Engineering, University of Canterbury.

Maeda, M., Ogawa, T., Kiyokawa, K. \& Takemura, H., 2004. Tracking of user position and orientation by stereo measurement of infrared markers and orientation sensing, International Symposium on Wearable Computers, pp. 77-84.

Marchand, E., Bouthemy, P. \& Chaumette F., 2001. A 2D-3D model-based approach to real-time visual tracking. Journal of Image and Vision Computing, 19(13): 941-955.

Meehan, M., Insko, B., Whitton, M. \& Boorks, F.P., 2002. Physiological measures of presence in stressful virtual environment, ACM Transactions on Graphics, 21 (3): 645-652.

Nakazato, Y., Kanbara, M. \& Yokoya, N., 2005. Localization of wearable users using invisible retroreflective markers and an IR camera, SPIE Electronic, 5664: 1234-1242.

Öst, L., Salkovskis, P. \& Hellstroöm, K., 1991. One-session therapist directed exposure vs. selfexposure in the treatment of spider phobia, Behavior Therapy, 22: 407-422.

Park, H. \& Park, J-II., 2004. Invisible marker tracking for AR, The third IEEE and ACM International symposium on mixed and augmented reality, pp. 272-273.

Pilet, J., 2008. Augmented Reality for Non-Rigid Surfaces, Doctoral Dissertation, Ecole Polytechnique federale de Lausanne, France, http://cvlab.epfl.ch/software/bazar (accessed on 18 March 2011).

Regenbrecht, H. T., Schubert, T. W. \& Friedmann, F., 1998. Measuring the sense of presence and its relations to fear of heights in virtual environments. International Journal of Human-Computer Interaction, 10(3): 233-249.

Renaud, P., Bouchard, S. \& Proulx, R., 2002. Behavioral avoidance dynamics in the presence of a virtual spider, IEEE Trans. on Information Technology in Biomedicine, 6(3): 235-243.

Rothbaum, B. O., Hodges, L., Kooper, R., Opdyke, D., Williford, J. S. \& North, M., 1995. Effectiveness of computer generated (virtual reality) graded exposure in the treatment of acrophobia. American Journal of Psychiatry, 152: 626-628.

Robillard, G., Bouchard, S., Renaud, P. \& Fournier, T., 2003. Anxiety and presence during VR immersion: A comparative study of the reactions of phobic and non-phobic participants in therapeutic virtual environments derived from computer games. CyberPsychology \& Behavior, 6(5): 467-476.

Sauer, F., Wenzel, F., Vogt, S., Tao, Y., Genc, T. \& Bani-Hashemi, A., 2000. Augmented workspace: designing an AR testbed, IEEE and ACM Int. Symp. on Augmented Reality, pp. 165-174.

Schuemie, M. J., Bruynzeel, M., Drost, L., Brinckman, M., de Haan, G. \& EmmelKamp, P. M. G., 2000. Treatment of acrophobia in virtual reality: A pilot study. In F. Broeckx \& L. Pauwels (Eds.), Euromedia 2000, 271-275.

Slater, M. \& Steed, A., 2000. A Virtual Presence Counter. Presence: Teleoperators and Virtual Environments, 9(5): 413-434.

Slater, M., Usoh, M. \& Steed, A., 1994. Depth of presence in virtual environments. Presence: Teleoperators and Virtual Environments, 3: 130-144.

State, A., Hirota, G., David, T., Garett, W. F. \& Livingston, M. A., 1996. Superior augmented-reality registration by integrating landmark tracking and magnetic tracking. In: Proceedings ACM SIGGRAPH, pp. 429-438.

Szymanski, J. \& O'Donohue, W., 1995. Fear of spiders questionnaire. Journal of Behavior Therapy and Experimental, Psychiatry, 26(1): 31-34.

Tenmoku, R., Kanbara, M. \& Yokoya, N., 2003. A wearable augmented reality system using positioning infrastructures and a pedometer, International Symposium on Wearable Computers, pp. $110-117$. 
Vacchetti, L., Lepetit, V. \& Fua, P., 2004. Combining edge and texture information for real-time accurate 3D camera tracking. The International Symposium on Mixed and Augmented Reality, pp. 48-57.

Watts, F.N. \& Sharrock, R., 1984. Questionnaire dimensions of spider phobia. Behaviour Research and Therapy, 22: 575-580.

Wiederhold, B. K., Jang, D. P., Gevirtz, R. G., Kim, S. I., Kim, I. Y. \& Wiederhold, M. D., 2002. The treatment of fear of flying: A controlled study of imaginal and virtual reality graded exposure therapy. IEEE Transactions on Information Technology in Biomedicine, 6(3): 218-222.

Witmer, B. \& Singer, M., 1998. Measuring presence in virtual environments: A Presence Questionnaire. Presence: Teleoperators \& Virtual Environments, 7(3), 225-240.

Xu, Y., Gandy, M., Deen, S., Schrank, B., Spreen, K., Gorbsky, M., White, T., Barba, E., Radu, I., Bolter, J. \& MacIntyre, B., 2008. BragFish: exploring physical and social interaction in co-located handheld augmented reality games, The International Conference on Advances in Computer Entertainment Technology, pp. 276-283.

Yasumuro, Y., Imura, M., Manabe, Y., Oshiro, O. \& Chihara, K., 2005. Projection-based augmented reality with automated shape scanning, In: Proceedings of SPIE, 5664: 555-562. 